\title{
An aid to successful probing of the nasolacrimal duct
}

\author{
J. D. ABRAMS \\ From the Royal Free Hospital, London
}

SUMMARY An electrical method is described for confirming the entry into the nose of a nasolacrimal probe.

The average ophthalmic surgeon is unlikely to flatter himself about his ability to visualise the lower end of the nasolacrimal duct, particularly in those patients, small infants, in whom an obstruction at this site may be of clinical importance. It has furthermore been suggested that the probing of the nasolacrimal duct in such patients may fail if the probe pushes a fold of mucosa ahead of it instead of perforating it.

\section{Materials and methods}

At the suggestion of my otorhinolaryngological colleague, Mr John Groves, I have found that true patency can be confirmed electrically. The probing is carried out under general anaesthesia by one of the standard methods. The lower canaliculus is probed first to investigate and ensure patency into the sac. The nasolacrimal duct is then probed via the upper canaliculus. With the No. 0 probe in position an electrode is clipped on to it which connects with a battery-activated light (Fig. 1). The other terminal from this is attached to a No. 1 lacrimal probe, which is then used to explore the inferior meatus of the nose. If and when it comes in contact with the end of the probe emerging from the nasolacrimal duct, the circuit is closed and the bulb lights.

The electrical circuit is easily constructed; it incorporates a $6 \mathrm{~V}$ battery and $2.7 \mathrm{~W}$ bulb.

\section{Discussion}

Some points of note are as follows. Firstly, the nasal probe has to be directed not only backwards but slightly outwards and even downwards to get under the inferior concha. Secondly, the time taken to establish electrical contact may help haemostasis in any area of the duct where the passage of the probe has led to rupture of small vessels.

Address for reprints: Mr J. D. Abrams, FRCS, 99 Harley Street, London W1N 1DF

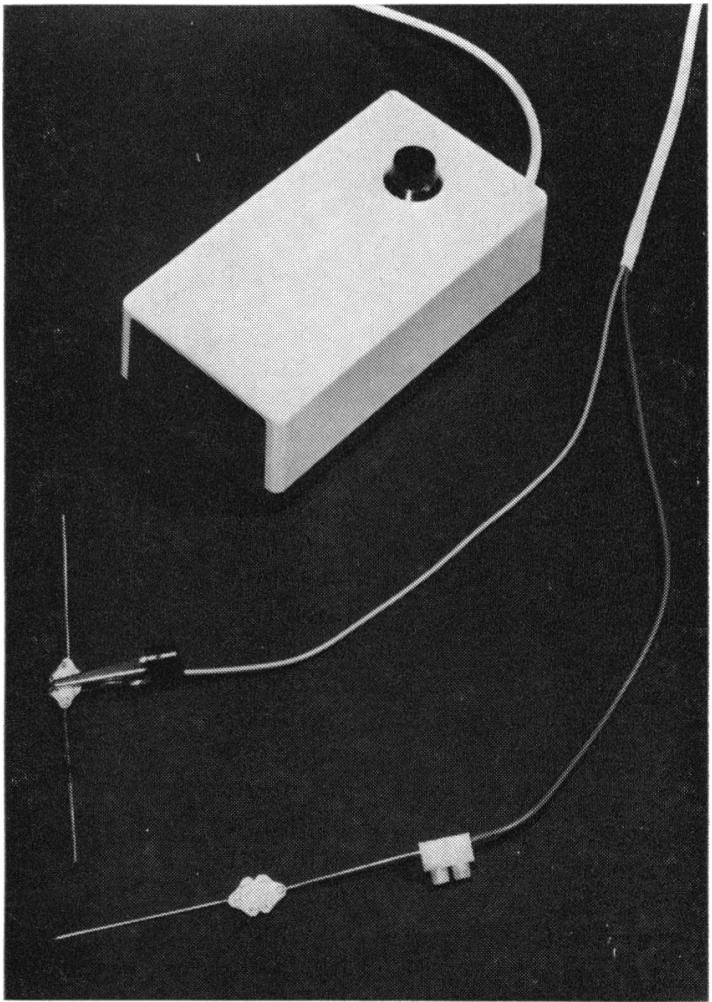

Fig. 1 Equipment for probing nasolacrimal duct

It is possible to make a rough estimate of the distance from upper punctum to the lower end of the duct. The probe is withdrawn up the nasolacrimal duct once electrical contact has been obtained until the light goes out. At the age of 12 months the distance is about 22 to $23 \mathrm{~mm}$.

Patency confirmed electrically at least partially avoids any indication to syringe lacrimal passages, a procedure for which a cautious anaesthetist would prefer to intubate the patient. Intubation is therefore unnecessary when this test is employed.

The inexperienced young surgeon may be un- 
certain how far to push the probe down the duct. He may be unaware of passing through any obstruction or there may indeed be none. This device makes it easier for him to determine objectively that he has got into the nasal cavity when, not having felt any resistance, he thinks he has gone down far enough.

Making and breaking the circuit not only activates the light, it may also cause a twitch of the orbicularis. There are, one supposes, simpler methods of electrical stimulation of the orbicularis, and here it raises the possibility of some therapeutic use as in the problem of residual watering in an all but completely recovered Bell's palsy.

My thanks are due to the workshops of the Neasden and Royal Free Hospitals and to the Photographic Department of the latter. 